\title{
PULMONARY TOXICITY OF SIMULATED LUNAR AND MARTIAN DUSTS IN MICE: I. HISTOPATHOLOGY 7 AND 90 DAYS AFTER INTRATRACHEAL INSTILLATION
}

\section{Chiu-Wing Lam}

\author{
Wyle Laboratories, NASA Johnson Space Center, Houston, Texas, USA
}

\section{John T. James, Richard McCluskey}

Space and Life Sciences, NASA Johnson Space Center, Houston, Texas, USA

\author{
Shawn Cowper, John Balis, Carlos Muro-Cacho \\ Department of Pathology, University of South Florida, Tampa, Florida, \\ USA
}

\begin{abstract}
NASA is contemplating sending humans to Mars and to the moon for further exploration. Volcanic ashes from Arizona and Hawaii with mineral properties similar to those of lunar and Martian soils, respectively, are used to simulate lunar and Martian environments for instrument testing. Martian soil is highly oxidative; this property is not found in Earth's volcanic ashes. NASA is concerned about the health risk from potential exposure of workers in the test facilities. Fine lunar soil simulant (LSS), Martian soil simulant (MSS), titanium dioxide, or quartz in saline was intratracheally instilled into groups of 4 mice (C57BL 6J) at $0.1 \mathrm{mg} /$ mouse (low dose, LD) or $1 \mathrm{mg} /$ mouse (high dose, HD). Separate groups of mice were exposed to ozone (0.5 ppm for $3 \mathrm{~h})$ prior to MSS instillation. Lungs were harvested for histopathological examination 7 or 90 days after the single dust treatment. The lungs of the LSS-LD groups showed no evidence of inflammation, edema, or fibrosis; clumps of particles and an increased number of macrophages were visible after 7 days but not 90 days. In the LSS-HD-7d group, the lungs showed mild to moderate alveolitis, and perivascular and peribronchiolar inflammation. The LSS-HD-90d group showed signs of mild chronic pulmonary inflammation, septal thickening, and some fibrosis. Foci of particle-laden macrophages (PLMs) were still visible. Lung lesions in the MSS-LD-7d group were similar to those observed in the LSS-HD-7d group. The MSS-LD-90d group had PLMs and scattered foci of mild fibrosis in the lungs. The MSS-HD-7d group showed large foci
\end{abstract}

Received 24 January 2001; sent for revision 9 February 2001; revision received 24 December 2001; accepted 29 December 2001.

The authors gratefully acknowledge Dr. Carlton Allen, Astromaterials Curator of the NASA Johnson Space Center, for providing the raw simulated Martian and lunar soils. Dr. Yung-Sung Cheng of Lovelace Respiratory Research Institute (Albuquerque, NM) is also gratefully acknowledged for preparing the fine soil samples from these raw materials. We thank Dr. Andij Holian and Judith Nelle of the University of Texas at Houston for valuable technical discussions. This study was supported by the NASA Johnson Space Center Director's Discretionary Fund and by a small grant from the University of South Florida.

Portions of this work were presented at the 39th Annual Meeting of the Society of Toxicology, March 2000, Philadelphia.

Address correspondence to Chiu-Wing Lam, Toxicology Group, Wyle Laboratories, Johnson Space Center, SF23, Houston, TX 77058, USA. E-mail: Chiu-wing.Lam@jsc.nasa.gov 
of PLMs, intra-alveolar debris, mild-to-moderate focal alveolitis, and perivascular and peribronchiolar inflammation. The MSS-HD-90d group showed focal chronic mild-to-moderate alveolitis and fibrosis. The findings in the $\mathrm{O}_{3}-\mathrm{MSS}-\mathrm{HD}-90 \mathrm{~d}$ group included widespread intra-alveolar debris, focal moderate alveolitis, and fibrosis. Lung lesions in the MSS groups were more severe with the ozone pretreatment. The effects of $\mathrm{O}_{3}$ and MSS coexposure appeared to be more than additive. Results for the $\mathrm{TiO}_{2}$ and quartz controls were consistent with the known pulmonary toxicity of these compounds. The overall severity of lung injury was $\mathrm{TiO}_{2}<L S S<M S S<\mathrm{O}_{3}+\mathrm{MSS}<$ quartz. Except for $\mathrm{TiO}_{2}$, the increased duration of dust presence in the lung from 7 to 90 days transformed the acute inflammatory response to a chronic inflammatory lesion. This study showed that LSS and MSS are more hazardous in the lungs than nuisance dusts.

NASA is considering returning to the Moon to establish a lunar outpost and sending humans to explore Mars (Hoffman \& Kaplan, 1997). Instruments and hardware destined for these extraterrestrial bases must be tested in simulated Martian and lunar environments in NASA laboratories. NASA has used ashes obtained from the San Francisco volcano field in Arizona and from a Hawaiian volcano for environmental simulation (Glaser, 1992). These volcanic ashes have mineral properties resembling those of lunar and Martian soils, respectively (McKay et al., 1994; Allen et al., 1998). Since the inhalation toxicity of these soil simulants has not been evaluated, NASA is concerned about the health risk to workers from potential dust exposures in the Earth-based test facilities. Toxicity testing with simulants can also provide guidance for designing experiments with actual lunar dust and eventually Martian dust.

During the first Apollo lunar landing, the moon dust particles encountered were described by the crew as extremely fine (NASA, 1969). The dust stuck to their spacesuits despite attempts to brush it off and was brought into the lunar landing vehicles. After the spacecraft lifted off from the lunar surface and microgravity was reestablished, a large quantity of floating dust made breathing difficult and impaired the visual acuity of the crew (NASA, 1970). NASA conducted a few studies in the 1970s to assess the risk of exposure, but the results failed to reveal whether the dust was an inhalation hazard (Holland \& Simmonds, 1972) (see Discussion for details). Russian investigators also conducted a few studies on lunar dust. They concluded that lunar soil caused fibrosis and other signs of pneumoconiosis in animals (Kustov et al., 1974, 1989). However, the studies contained considerable experimental deficiencies (see Discussion for details). The toxicity of lunar dust must be further determined before humans are sent to the Moon for long periods of habitation. In general, NASA will not release a lunar sample for study until a successful study on the simulant (JSC-1) has been conducted. Addressing this requirement was one of the purposes of the present study.

The composition of the lunar simulant is a good match for its extraterrestrial counterpart; a detailed comparison has been published by McKay et al. (1994). In brief, both the lunar soil and its simulant contain about $50 \%$ $\mathrm{SiO}_{2}$; other common soil oxides $\left(\mathrm{Al}_{2} \mathrm{O}_{3}, \mathrm{FeO}, \mathrm{MgO}\right.$, and $\left.\mathrm{CaO}\right)$ account for 
another $42 \%$ to $45 \%$. No trace or heavy metals were found. The particlesize distribution (average about $100 \mu \mathrm{m}$ ) of the simulant fits within the range of lunar samples returned by Apollo missions. The simulant contains about $1 \%$ respirable dust (see Methods).

Martian surface soil is similar to Hawaiian volcanic ash in mineral content (Allen et al., 1998). Martian soil and the simulant (after removal of water and other volatiles) both contain about $45 \% \mathrm{SiO}_{2}$ and $15 \% \mathrm{Fe}_{2} \mathrm{O}_{3}$, which imparts a brown color to both the regolith and its simulant. The other components that account for the majority of the remaining bulk are $\mathrm{Al}_{2} \mathrm{O}_{3}, \mathrm{CaO}, \mathrm{TiO}_{2}, \mathrm{MgO}, \mathrm{Na}_{2} \mathrm{O}$, and $\mathrm{K}_{2} \mathrm{O}$. No trace or heavy metals have been found. Only $1 \%$ of the simulant is smaller than $5 \mu \mathrm{m}$. Detailed comparison of the Martian soil with its simulant can be found in a report published by Allen et al. (1998).

Martian soil is reactive; the evidence comes from experiment results obtained by the Viking Martian lander. When surface soil samples on Mars were humidified, evolution of oxygen was observed, suggesting the presence of superoxides or peroxides on the soil (Oyama \& Berdahl, 1977). Reactive and oxidative species in Martian analog soil were recently produced under simulated Martian surface conditions (Yen et al., 2000; Tsapin et al., 2000). Inhalation exposures to Martian regolith would be expected to produce lesions in the lung partially resembling those caused by powerful oxidants. Since oxidatively activated Martian analog soil was not available at the time of this study, an ozone exposure of the mice followed by an intratracheal instillation with the unactivated ash was included to simulate the effects of the oxidative properties of Martian soil in the lung. Ozone was chosen because its effects in the lung have been well characterized, and it was feasible to select a dose that would produce only minimal tissue injury so the combined effects could be discerned.

\section{MATERIALS AND METHODS}

\section{Simulated Martian and Lunar Dusts}

Raw Arizona and Hawaii volcanic ashes [designated as JSC-1 (McKay et al., 1994) and JSC-Mars-1 (Allen et al., 1998)] were provided to Lovelace Respiratory Research Institute for size fractionation. According to the procedure used at Lovelace (Cheng, personal communication, 1998), the raw material was placed in a DeVilbiss dry powder generator operated with compressed air at 20 psig; the output was then delivered to a 3-stage cyclone operated at $31 \mathrm{~L} / \mathrm{min}$ (Smith et al., 1979). The cutoff aerodynamic diameters were $5,1.95$, and $0.28 \mu \mathrm{m}$ for the 3 stages. The fine particles from the second and third stages and the backup filter were collected and pooled for the present study. Thus, the mass median aerodynamic diameter (MMAD) of both soils was expected to be less than $5 \mu \mathrm{m}$.

Because the present study was not conducted by the inhalation route (for which particle sizes are important in determining the fractional deposi- 
tion of inhaled particles into the pulmonary region), the simulants were used without further characterization of particle-size distribution before the intratracheal instillation study. Some time after the intratracheal instillation study was completed, Microtrac, Inc. (Montgomeryville, PA), offered to determine particle sizes of the simulated dusts using their newly marketed instrument. In Microtrac's assay, approximately $50 \mathrm{mg}$ of the LSS or MSS was suspended in $200 \mathrm{ml}$ of distilled water and placed in the reservoir chamber of a Microtrac X-100 particle-size analyzer. This trilaser analytical unit was connected to a computer unit for data acquisition and analysis. The instrument has a particle size analytical range of 0.04 to $700 \mu \mathrm{m}$ separated into 120 channels. Timed ultrasonication, which is controlled by the computer, can be generated in the reservoir chamber to ensure that the particles remain homogeneously suspended. The distribution profiles showed that the respirable fraction of the LSS had mass median diameters (MMDs) of $3 \mu \mathrm{m}$ or less, and contained 5\% large particles with MMD of $81 \mu \mathrm{m}$; upon ultrasonication, all of the large particles disappeared and the resulting suspension showed a bimodal distribution, with MMDs of $1.05 \mu \mathrm{m}(44 \%)$ and $2.99 \mu \mathrm{m}(56 \%)$. The MSS isolated similarly had a bimodal distribution that included a mass fraction with $70 \%$ fine dust with a mass median diameter $(\mathrm{MMD})$ of $3 \mu \mathrm{m}$ and $30 \%$ particles with MMD of $108 \mu \mathrm{m}$ (diameters ranging from 30 to $400 \mu \mathrm{m}$ ). To our surprise, repeated ultrasonications still could not significantly change this particle-distribution profile.

\section{Titanium Dioxide and Crystalline Silica}

The titanium dioxide sample, a product of Particle Information Services (Kingston, MA), had an average particle diameter of $0.45 \mu \mathrm{m}$. Crystalline silica (quartz) (acid-washed Min-U-Sil-5) with an average particle size of 5 $\mu \mathrm{m}$ was obtained from Pennsylvania Glass and Sand (Pittsburgh, PA). These particle-size specifications were from the respective vendors.

\section{Animals and Animal Husbandry}

Male mice (C57BL/6J, 2 mo old), free of known rodent pathogens, were obtained from Jackson Laboratory (Bar Harbor, ME). The animals were housed in groups of four in polycarbonate cages (with HEPA air filters) in the AAALAC-accredited vivarium at the Johnson Space Center (JSC). Animals were allowed to acclimate at this facility (with a 12-h light-dark cycle) for at least $1 \mathrm{wk}$ before being used in the study. The mice had free access to tap water and Purina Formulab Chow number 50008 (Ralston Purina Co., St. Louis, MO). They were cared for and used humanely according to NASA Animal Care and Use Program guidelines.

\section{Inhalation Exposure to Ozone}

The animals in the MSS study that required a preexposure to ozone were placed in a $0.75-\mathrm{m}^{3}$ Laskin-type stainless steel exposure chamber (Wahman, MD) (Kirichenko et al., 1996). Ozone was generated by passing house air through an electrical ozone generator (model V5AR-237 ozona- 
tor, Ozone Research Equipment Corp, Phoenix, AZ); it was then metered and mixed with house air before entering the chamber. A small air stream was pulled $(2 \mathrm{~L} / \mathrm{min})$ from the chamber through Teflon tubing into a calibrated ozone monitor (model 1003AH, Dasibi Environmental Corporation, Glendale, CA). The monitor was calibrated shortly before this study by a laboratory at the U.S. Environmental Protection Agency (Houston Regional Office). After the chamber ozone concentration had been stabilized at 0.5 ppm, 6 groups of mice (4 mice/group) were placed in the chamber for $3 \mathrm{~h}$ and the ozone concentration was recorded every $10 \mathrm{~min}$. The exposure level was selected to produce no more than minimal tissue injury.

\section{Intratracheal Instillation of Dust Samples}

Each mouse was anesthetized intraperitoneally with a cocktail of 150 $\mathrm{ml}$ of ketamine and xylazine at a dose of about 80 and $16 \mathrm{mg} / \mathrm{kg}$, respectively. After the animal was labeled with an ear tag and body weight was determined, it was secured on an inclined plastic platform (about $60^{\circ}$ ). The trachea was exposed by a $1-\mathrm{cm}$ incision on the ventral neck skin (Leigh et al., 2000). An aliquot of $50 \mu \mathrm{l}$ of freshly suspended and ultrasonicated dust in normal saline, containing $0.1 \mathrm{mg}$ (LD) or $1 \mathrm{mg}$ (HD) dust, was intratracheally instilled (using a 26-g needle) into the lung. For the saline-only and ozone-only control animals, only saline was instilled. The incision was then sutured and swabbed with Povidone iodine. The mice of each treatment group (4/group) were caged together in the vivarium and observed daily until their scheduled termination.

\section{Collection of Lungs from Animals for Histopathological Study}

Seven or 90 days after the dust treatment, each mouse was injected intraperitoneally with a lethal dose of pentobarbital sodium solution (Nembutal, Abbott, North Chicago, IL). Body weight was determined. An incision was made to expose the trachea for inserting a catheter; formalin $(10 \%$ in a neutral phosphate buffer) was allowed to drip by gravity (from a 25 -cc syringe barrel hanging $1.5 \mathrm{ft}$ above the neck) through the catheter into the lung for about $10 \mathrm{~min}$. The trachea was then tied and the isolated lung was placed in a glass vial containing about $10 \mathrm{ml}$ of the same fixative. Each glass vial was assigned a number unknown (with respect to treatment) to the pathologists. The lungs were fixed for at least 7 days before further processing.

\section{Preparation of Lung Tissue Slides for Histopathological Examination}

The formalin-fixed mouse lungs were embedded in paraffin, thin-sectioned coronally, and mounted on glass microscope slides using standard histopathological techniques. Sections were stained with hematoxylineosin. For each mouse, one slide containing one lung section was examined independently by three pathologists. Van Gieson and trichrome stains were also used to stain elastin and connective tissue to provide supplementary information to the pathologists. A formated score sheet was used for grading intraalveolar, interstitial, vascular, and bronchiolar/bronchial areas for 
the presence of particles, macrophages, inflammation cells, edema, congestion, hyperplasia, fibrosis, and other parameters (when applicable). The scores from the three pathologists were averaged.

\section{RESULTS}

\section{Effects of Instilled Titanium Dioxide}

After receiving a single intratracheal instillation of $\mathrm{TiO}_{2}(0.1 \mathrm{mg} / \mathrm{mouse}$, low dose, LD), the lungs of the mice killed 7 days after the treatment showed focal clumps of particles; some of the particles were inside macrophages. There was no evidence of inflammation, edema, or fibrosis (Table 1). The lungs of the mice that were killed 90 days after dust treatment had no identifiable particles and were completely normal (Figure 1A). This slide, which is indistinguishable from those of the saline-treated controls, is used in this manuscript for illustrating the appearance of normal lung tissue and treatment with a negative-control dust.

TABLE 1. Summary of lung histopathology results from intratracheally instilled mice

\begin{tabular}{|c|c|c|c|c|c|c|}
\hline Treatment & $\begin{array}{l}\text { Dust dose } \\
\text { (mg/mouse) }\end{array}$ & Day & $\uparrow$ Macrophages & Inflammation & Edema & Fibrosis \\
\hline Saline & 0 & 7 & 0 & 0 & 0 & 0 \\
\hline $\mathrm{O}_{3}(0.5 \mathrm{ppm})$ & 0 & 7 & 0 & 0 & 0 & 0 \\
\hline $\mathrm{TiO}_{2}$ & 0.1 & 7 & + & 0 & 0 & 0 \\
\hline LSS & 0.1 & 7 & + & 0 & 0 & 0 \\
\hline MSS & 0.1 & 7 & + & + & 0 & 0 \\
\hline $\mathrm{MSS}+\mathrm{O}_{3}(0.5 \mathrm{ppm})$ & 0.1 & 7 & + & + & 0 & 0 \\
\hline $\mathrm{SiO}_{2}$ & 0.1 & 7 & + & ++ & + & 0 \\
\hline Saline & 0 & 90 & 0 & 0 & 0 & 0 \\
\hline $\mathrm{O}_{3}(0.5 \mathrm{ppm})$ & 0 & 90 & 0 & + & 0 & 0 \\
\hline $\mathrm{TiO}_{2}$ & 0.1 & 90 & 0 & 0 & 0 & 0 \\
\hline LSS & 0.1 & 90 & 0 & 0 & 0 & 0 \\
\hline MSS & 0.1 & 90 & + & + & 0 & + \\
\hline $\mathrm{MSS}+\mathrm{O}_{3}(0.5 \mathrm{ppm})$ & 0.1 & 90 & + & + & 0 & + \\
\hline $\mathrm{SiO}_{2}$ & 0.1 & 90 & + & + & 0 & + \\
\hline $\mathrm{TiO}_{2}$ & 1.0 & 7 & + & 0 & 0 & 0 \\
\hline LSS & 1.0 & 7 & + & + & 0 & 0 \\
\hline MSS & 1.0 & 7 & ++ & + & + & 0 \\
\hline $\mathrm{MSS}+\mathrm{O}_{3}(0.5 \mathrm{ppm})$ & 1.0 & 7 & ++ & ++ & 0 & + \\
\hline $\mathrm{SiO}_{2}$ & 1.0 & 7 & ++ & +++ & ++ & 0 \\
\hline $\mathrm{TiO}_{2}$ & 1.0 & 90 & ++ & + & 0 & 0 \\
\hline LSS & 1.0 & 90 & + & + & 0 & + \\
\hline MSS & 1.0 & 90 & + & + & 0 & + \\
\hline $\mathrm{MSS}+\mathrm{O}_{3}(0.5 \mathrm{ppm})$ & 1.0 & 90 & ++ & ++ & + & ++ \\
\hline $\mathrm{SiO}_{2}$ & 1.0 & 90 & ++ & +++ & ++ & ++ \\
\hline
\end{tabular}

Note. Groups of 4 mice were intratracheally instilled with $0,0.1$, or $1 \mathrm{mg}$ of a dust per mouse and killed 7 or 90 days after the single treatment. The results in the table were condensed from formated score sheets, which recorded intraalveolar, interstitial, vascular, and bronchiolar/bronchial areas for relevant histopathological parameters. 

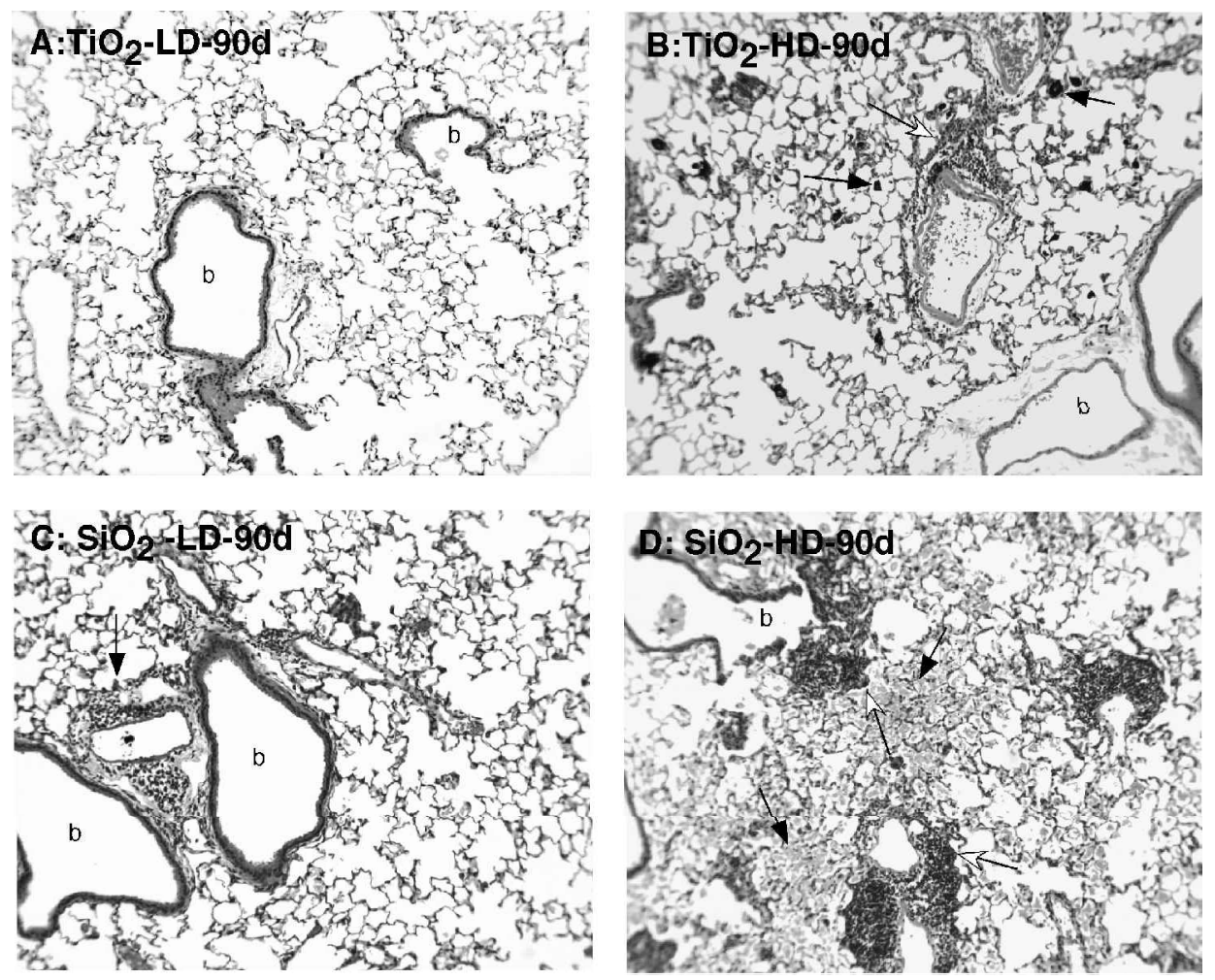

FIGURE 1. Lung histopathology of mice intratracheally instilled with a single dose of $0.1 \mathrm{mg}$ (LD) or 1 mg (HD) of $\mathrm{TiO}_{2}$ or quartz. The animals were killed 90 days after the dust treatment. The lung histology of mice in the $\mathrm{TiO}_{2}$-LD-90d (A) was indistinguishable from that of saline controls, therefore, (A) is also used to illustrate normal lung histology. In the figures, $b=$ bronchus, $v=$ vessel; in (B), $\rightarrow=$ focal mild perivasular inflammation, $\rightarrow$ = clumps of particles; $(C)$ shows mild focal fibrosis, $\rightarrow=$ mild perivascular and peribronciolar inflammation; (D) shows moderate aleveolitis, severe focal fibrosis, $\rightarrow=$ moderate to severe perivascular and peribronchiolar inflammation, $\rightarrow=$ intraalveolar debris and edema. Magnification: $\times 200$.

When compared to the lungs of low-dose animals of the same treatment duration, lungs of mice in the high-dose group $(1 \mathrm{mg} / \mathrm{mouse})$ that were killed 7 days after the dust treatment had larger focal clumps of particles; the HD-90d group had increased numbers of alveolar macrophages and mild focal perivascular inflammation (Figure 1B).

\section{Effects of Instilled Quartz}

The lungs of the $\mathrm{SiO}_{2}-\mathrm{LD}-7 \mathrm{~d}$ group showed focal clumps of particles and an increased number of alveolar macrophages. Mild to moderate focal alveolar inflammation, mild focal perivascular and peribronchiolar inflammation, neutrophilic and lymphocytic infiltration, and edema also were observed. The lungs of mice in the $\mathrm{SiO}_{2}$ - $\mathrm{LD}$ group killed 90 days after dust treatment still had clumps of particles and particle-laden macrophages (PLMs) in addition to mild inflammation and mild focal fibrosis (Figure 1C). 
The lungs of the HD-7d group contained larger focal clumps of particles and more macrophages compared with the lungs of the LD-7d group. In addition, the lung lesions were more severe, showing moderate to severe alveolitis, moderate focal perivascular and peribronchiolar inflammation, and edema. For the high-dose group in the 90-day study, large clumps of PLMs were still abundant in the lungs. The lungs also showed moderate alveolitis; moderate to severe focal bronchiolar, perivascular, and peribronchiolar inflammation; necrosis; edema; and focally severe fibrosis, strongly resembling bronchiolitis obliterans organizing pneumonia (Figure 1D).

\section{Effects of Instilled Lunar Soil Simulant (LSS)}

The lungs of mice in the LSS-LD-7d group showed the presence of focal clumps of particles and, occasionally, macrophages (Figure 2A). There was no evidence of inflammation, edema, or fibrosis. At 90 days, particles were not observed and the tissue was normal (Figure 2B).
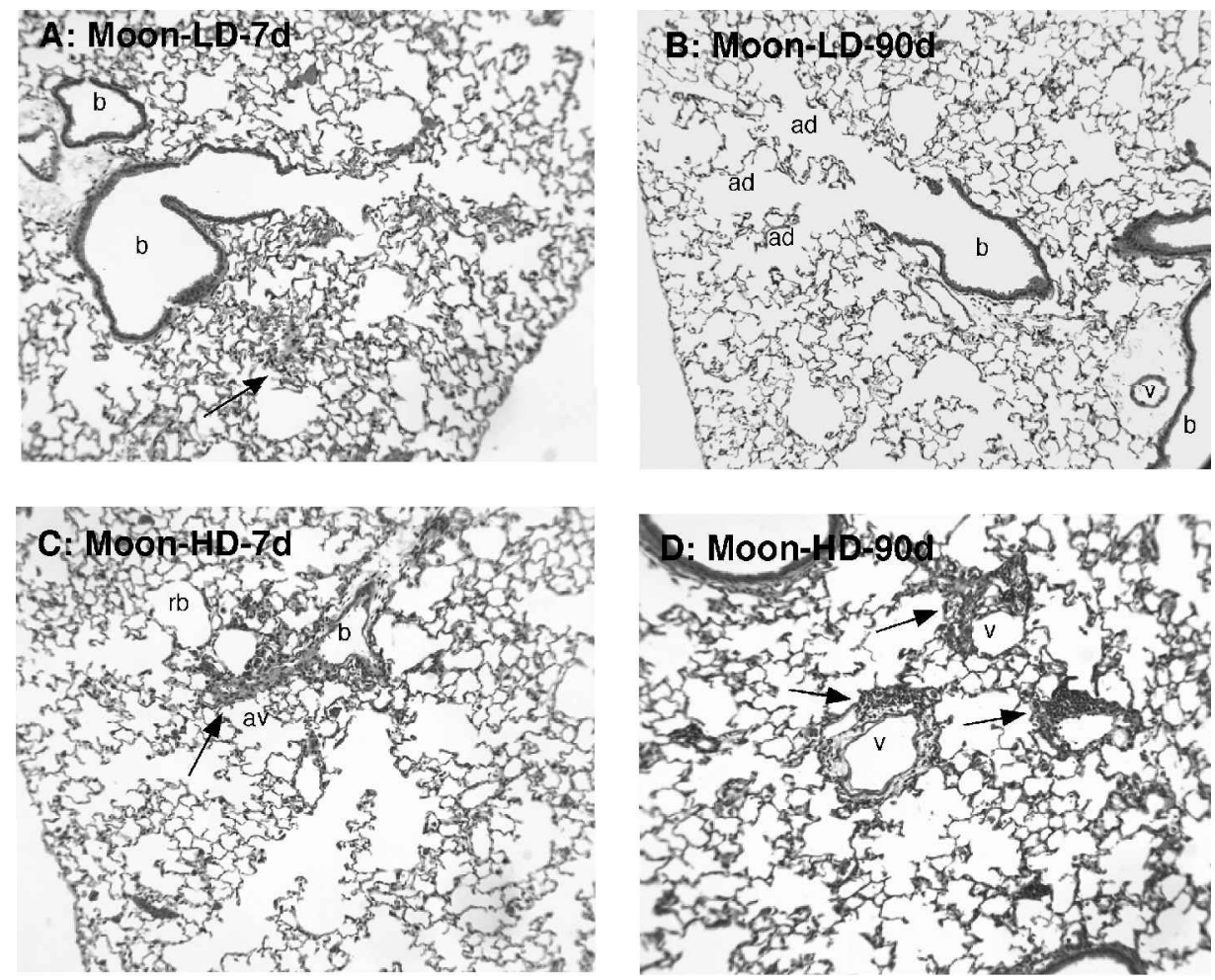

FIGURE 2. Lung histopathology of mice intratracheally instilled with a single dose of $0.1 \mathrm{mg}$ (LD) or $1 \mathrm{mg}$ (HD) of lunar soil simulant and killed 7 or 90 days after the treatment. In the figures, ad = alveolar duct, $\mathrm{b}=$ bronchus, $\mathrm{rb}=$ respiratory bronchus, $\mathrm{v}=$ vessel; in $(\mathrm{A}), \rightarrow=$ particle-laden macrophages; (B) shows normal tissue and no particles; (C) shows mild to moderate alveolitis with lymphocyte and neutrophile infiltration, $\rightarrow$ = alveolar damage, particle-laden macrophages, and inflammatory cells; (D) shows mild alveolitis, $\rightarrow=$ septal thickening, and blood vessel and bronchial inflammation. Magnification: $\times 200$. 

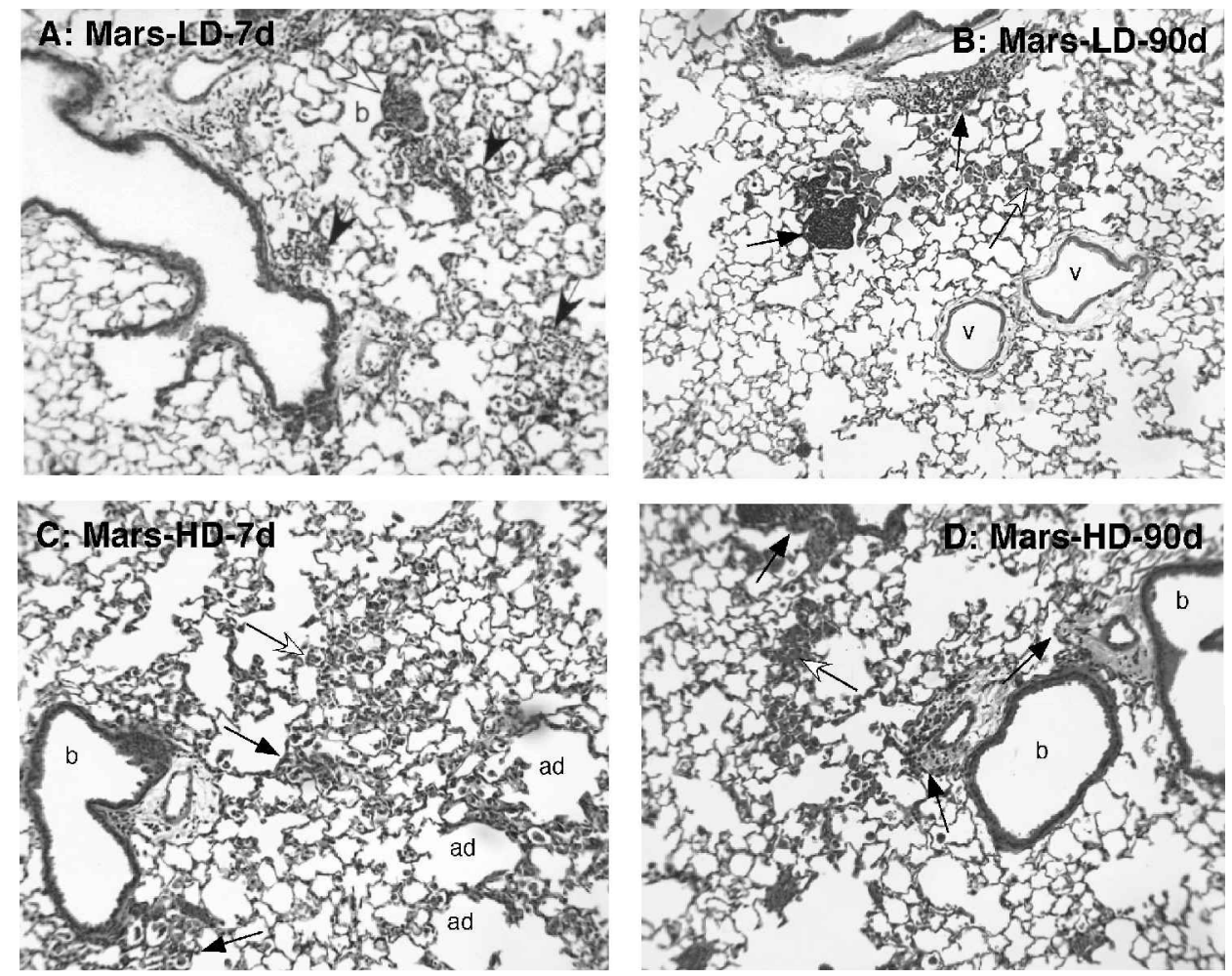

FIGURE 3. Lung histopathology of mice intratracheally instilled with a single dose of $0.1 \mathrm{mg}$ (LD) or 1 mg (HD) of Martian soil stimulant and killed 7 days or 90 days after the dust treatment. In the figures, $\mathrm{ad}=$ alveolar duct, $\mathrm{b}=$ bronchus, $\mathrm{v}=$ vessel; in $(\mathrm{A}), \rightarrow=$ inflammation cells and scattered debris, $\rightarrow=$ focal inflammation and fibrosis; in (B), $\rightarrow=$ particle-laden macrophages, $\rightarrow=$ fibrotic foci and inflammatory cells; in (C), $\rightarrow=$ particle-laden macrophages, $\rightarrow=$ inflammatory and intraalveolar debris; in $(D), \rightarrow=$ particle-laden macrophages, $\rightarrow=$ inflammation and fibrosis. Magnification: $\times 200$.

The lungs of mice in the HD-7d group showed clumps of particles and macrophages, mild to moderate alveolitis with neutrophilic and lymphocytic infiltration, and mild perivascular and peribronchiolar inflammation (Figure 2C). When they were examined 90 days after the dust treatment, foci of PLMs, mild alveolitis, mild focal perivascular and peribronchiolar chronic inflammation, and septal thickening were visible (Figure 2D).

\section{Effects of Instilled Martian Soil Simulant (MSS)}

The lungs of mice in the MSS-LD-7d group showed particles and macrophages; mild focal intra-alveolar debris, infiltration of neutrophils and lymphocytes, and perivascular and peribronchiolar inflammation were evident (Figure 3A). At 90 days, PLMs and scattered foci of mild fibrosis were detected (Figure 3B).

The lungs of the HD-7d group had large foci of PLMs, mild focal alveolitis, intra-alveolar debris, and mild to moderate perivascular and peri- 
bronchiolar inflammation (Figure 3C). At 90 days, PLMs, mild alveolitis, focal moderate inflammation, and fibrosis were observed (Figure 3D).

\section{Effects of Ozone and Instilled MSS}

A single 3 -h inhalation exposure to $0.51 \pm 0.02 \mathrm{ppm}$ ozone (followed by saline instillation) produced no overt lung injury when lungs were examined 7 days after the exposure; when they were examined 90 days after the exposure, mild focal alveolitis and peribronchiolar inflammation were noted. When an ozone exposure was followed by an intratracheal instillation of MSS ( $0.1 \mathrm{mg}$ or $1 \mathrm{mg} /$ mouse), the lungs of the LD-7d group showed foci of particles and an increase in macrophages. Focal mild peribronchiolar inflammation and alveolitis also were visible (Figure 4A). At 90 days, the lungs of the $\mathrm{O}_{3}+$ MSS-LD mice revealed focal mild peribronchiolar inflammation, alveolitis, and fibrosis (Figure 4B).

Lungs of $\mathrm{O}_{3}+$ MSS-HD-7d group showed large foci of PLMs, focal moderate peribronchiolar inflammation, alveolitis, intraalveolar debris, and early focal moderate to severe fibrosis (Figure 4C). The HD-90d group had widespread intraalveolar debris, alveolitis, and focal moderate inflammation and fibrosis (Figure 4D).

\section{Body Weight Changes after Instillation of the Dusts}

There were no statistically significant differences in body weight gains between the exposed groups and control groups killed either on 7 or 90 days after instillation of the dusts. After 7 days, the group average body weight gains ranged from a low of $-0.3 \mathrm{~g}(0.1 \mathrm{mg} \mathrm{MSS})$ to $+2.2 \mathrm{~g}$ (ozone control group). After 90 days, the weight gains ranged from $4.0 \mathrm{~g}$ to $6.4 \mathrm{~g}$. The groups with the lowest average body weight gains were the $\mathrm{O}_{3}+\mathrm{MSS}-\mathrm{HD}(4.0 \pm 1.6$ g), $\mathrm{SiO}_{2}$-LD (4.6 $\left.\pm 1.3 \mathrm{~g}\right)$, and $\mathrm{SiO}_{2}-\mathrm{HD}(4.9 \pm 0.7 \mathrm{~g})$ groups. These were among the groups that showed more severe histopathological effects in the lungs.

\section{DISCUSSION}

The present histopathology study and a lavage study (see companion paper, Lam et al., 2002) were conducted to assess the pulmonary toxicity of simulated Martian and lunar dusts. Another goal was to establish experiment protocols that could be applied to the study of lunar soil and eventually Martian soil. We anticipate that the quantity of extraterrestrial dusts in the respirable range that NASA could make available for toxicology studies will be very small. Inevitably, mice would be the animal species of choice and intratracheal instillation would be the route of administration to conserve the scarce dusts. Thus, this animal model and route of exposure were selected for the present study, with $\mathrm{TiO}_{2}$ and crystalline silica serving as negative and positive controls.

The doses for intratracheal instillation in this study were chosen on the basis of information from Henderson et al. (1995). Henderson reported that 

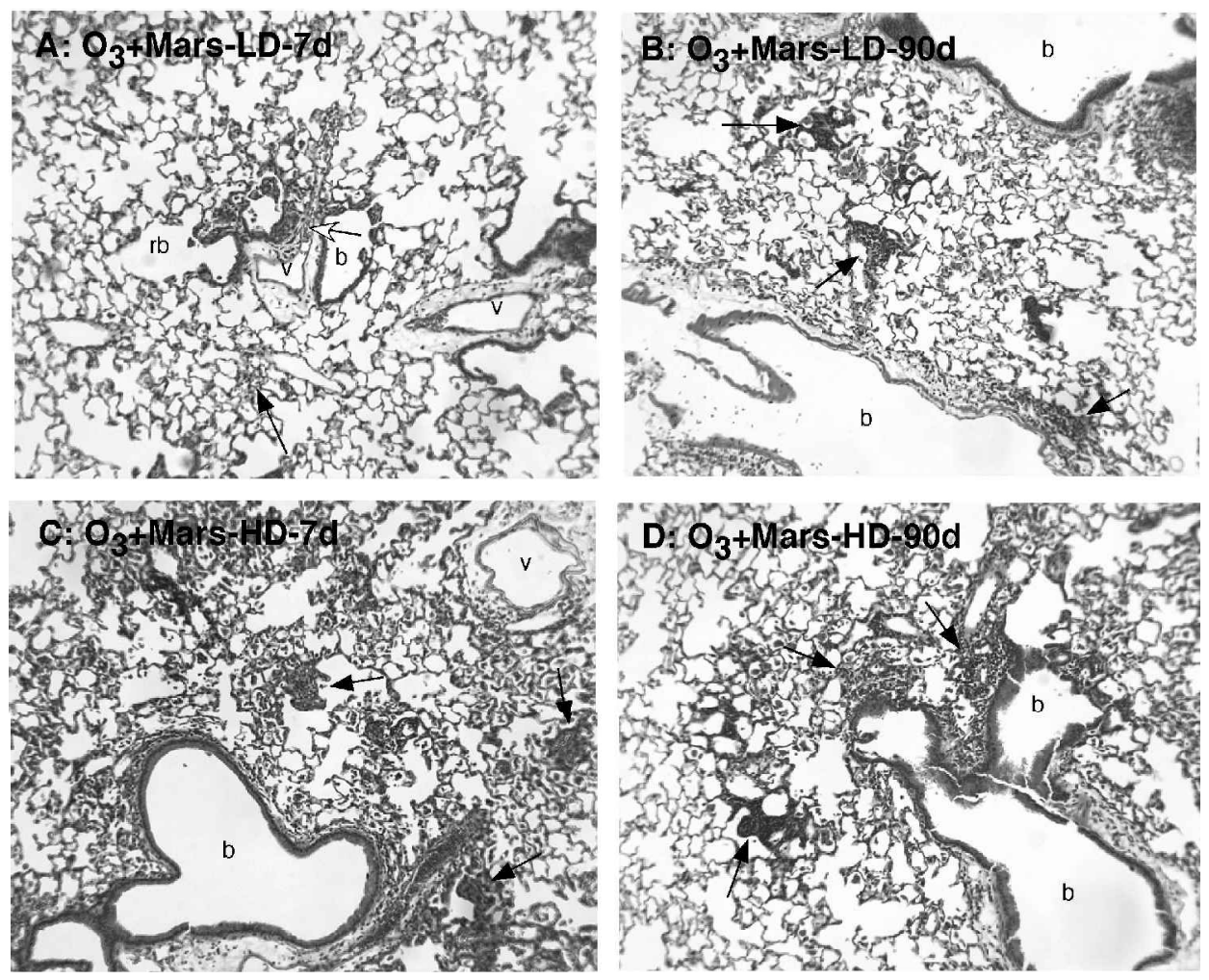

FIGURE 4. Lung histopathology of ozone-pretreated mice when each was intratracheally instilled with a single dose of $0.1 \mathrm{mg}(\mathrm{LD})$ or $1 \mathrm{mg}$ (HD) of Martian soil simulant and killed 7 days or 90 days after the dust treatment. The ozone exposure was for $3 \mathrm{~h}$ at $0.5 \mathrm{ppm}$. In the figures, $\mathrm{ad}=$ alveolar duct, $\mathrm{b}=$ bronchus, $r b=$ respiratory bronchus, $v=$ vessel; in $(A), \rightarrow=$ peribronchial inflammation, $\rightarrow=$ focal inflammation; in (B), $\rightarrow=$ focal inflammation and fibrosis; in (C), $\rightarrow=$ focal inflammation, alveolitis, and intraalveolar debris; in (D), $\rightarrow \mathbf{=}=$ septal thickening, fibrosis, wide-spread intraalveolar debris, and alveolitis. Magnification: $\times 200$.

in rats exposed by inhalation to $10 \mathrm{mg} / \mathrm{m}^{3}$ of quartz or $\mathrm{TiO}_{2}$ for $1 \mathrm{wk}$, the lung contained $0.76 \mathrm{mg}$ quartz or $0.44 \mathrm{mg} \mathrm{TiO}_{2}$. Information compiled by Boggs (1992) and Lai (1992) shows that the minute respiratory volume (MRV) of a 300-g rat, a 35-g mouse, and a 20-g mouse was 0.210, 0.040, and $0.025 \mathrm{~L} / \mathrm{min}$, respectively. The MRV of the mice (average $25 \mathrm{~g}$ ) in our study would be about $0.030 \mathrm{~L} / \mathrm{min}$. If it is assumed that dust deposition in the lung is roughly proportional to the MRV of the exposed animals, then if Henderson et al. (1995) had included mice ( $25 \mathrm{~g})$ in their study, the dust burden of the mouse lung would have been about $0.11 \mathrm{mg}$ quartz or 0.06 $\mathrm{mg} \mathrm{TiO}_{2}$. In the present study, a single dose of $0.1 \mathrm{mg}$ per mouse was chosen as a low dose and $1 \mathrm{mg}$ as a high dose.

Bermudez et al. (2000) reported that the lung burdens (determined at the end of the last exposure) of mice exposed to $\mathrm{TiO}_{2}$ at 10, 50, or $250 \mathrm{mg} /$ 
$\mathrm{m}^{3}$ for $13 \mathrm{wk}(6 \mathrm{~h} /$ day, 5 days $/ \mathrm{wk})$ were $5.2,53.5$, and $170.2 \mathrm{mg} / \mathrm{g}$ of dry lung tissue respectively (Bermudez et al., 2000). The corresponding values for lung burden of $\mathrm{TiO}_{2}$ per mouse calculated by these authors were approximately 0.2, 2, and $13 \mathrm{mg}$ (Bermudez, 2000, personal communication). It is noteworthy that the low dose $(0.1 \mathrm{mg} /$ mouse $)$ used in our study fell between the values for lung $\mathrm{TiO}_{2}$ burden of mice exposed to $10 \mathrm{mg} / \mathrm{m}^{3}$ for 1 wk $(0.06 \mathrm{mg} / \mathrm{mouse}$, extrapolated above using Henderson's data) and those exposed to $10 \mathrm{mg} / \mathrm{m}^{3}$ for $13 \mathrm{wk}(0.2 \mathrm{mg} /$ mouse; Bermudez, 2000, personal communication). The high dose in our study $(1 \mathrm{mg} / \mathrm{mouse})$ was half the value of the body burden of mice exposed to $50 \mathrm{mg} / \mathrm{m}^{3}$ for $13 \mathrm{wk}$ in Bermudez's study. This information is useful for quantitative comparisons of dust exposures by different route of pulmonary administrations, as long as the bolus nature of the intratracheal instillation is recognized (Driscoll et al., 2000). It also should be noted that the residual lung burden determined at the end of the last inhalation exposure is the dynamic result of cumulative intermittent deliveries and continuous elimination.

When the mice were each intratracheally instilled with $0.1 \mathrm{mg} \mathrm{of} \mathrm{TiO}_{2}$ particles, an increased number of macrophages, compared with that in the lung of saline controls, was seen 7 days after treatment. This increase was not visible 90 days after treatment and the lung tissue was apparently normal. When treated with a high $\mathrm{TiO}_{2}$ dose $(1 \mathrm{mg} /$ mouse $)$ and killed 90 days after dust instillation, the mice had particles persisting in their lungs, and numerous macrophages were present. Tissue histopathological manifestations were minimal. These findings were consistent with the observations reported by Bermudez et al. (2000) and colleagues (Everitt et al., 2000). In their studies, the lungs of the mice exposed for 90 days to $50 \mathrm{mg} / \mathrm{m}^{3}\left(\mathrm{TiO}_{2}\right.$ lung burden of $\sim 2 \mathrm{mg}$ ) had increased numbers of macrophages and neutrophils and "elevated soluble indices of inflammation." These parameters remained elevated when lungs were examined at $26 \mathrm{wk}$ after the last exposure. The increases were not observed in mice exposed to $10 \mathrm{mg} / \mathrm{m}^{3}$ (lung burden $\sim 0.2 \mathrm{mg}$ ).

For those animals instilled with $0.1 \mathrm{mg} /$ mouse and killed 90 days after treatment, MSS and $\mathrm{SiO}_{2}$ particles, but not LSS and $\mathrm{TiO}_{2}$, were still visible in the lungs. This observation indicated that $\mathrm{TiO}_{2}$ and LSS were easier to clear from the lungs than MSS and $\mathrm{SiO}_{2}$. However, when the animals were given $1 \mathrm{mg} /$ mouse, all 4 dusts were visible in the lung regardless of whether the animals were killed 7 or 90 days after dust treatment. The high doses apparently overwhelmed the pulmonary clearance mechanisms.

As mentioned earlier, particle size characterization after the instillation studies showed that the respirable fraction of LSS ultrasonicated in water had a bimodal distribution with mass median diameters (MMDs) of $1 \mu \mathrm{m}$ (44\%) and $3 \mu \mathrm{m}$ (56\%). The MSS prepared similarly had a bimodal distribution that included a mass fraction of $70 \%$ fine dust with an MMD of $3 \mu \mathrm{m}$ and $30 \%$ particles with an MMD of $108 \mu \mathrm{m}$ (diameters ranging from 30 to $400 \mu \mathrm{m})$, which is not in the respirable range. Repeated ultrasonications 
did not significantly diminish the population of these large particles. Thus, about $30 \%$ of the mass of the MSS given to the mice consisted of particles in the nonrespirable range. In general, per unit weight, toxic insults to the lung from particles decrease with an increase in particle size because a fine dust sample contains a much greater number of particles than a coarse sample of equal weight. The presence of large particles in MSS would quantitatively, but not qualitatively, influence the dose response. However, large particles, which are more difficult for macrophages to phagocytize, would be more persistent in the lung, and this fact may partially explain why MSS was more persistent than LSS in the lung.

LSS was more toxicologically reactive than $\mathrm{TiO}_{2}$ in the mice; the difference was more evident at the high dose. Like $\mathrm{TiO}_{2}$, LSS at the low dose produced very little tissue response. At the high dose, acute mild to moderate inflammation of the lung tissue was observed among the LSS-treated mice. With the continuous irritation of the high-dose LSS dust in the lung, acute inflammation observed in the 7-day group was transformed into chronic inflammation, which was observed 90 days after dust treatment. However, the inflammatory manifestations were relatively mild with this dust. MSS elicited a more severe reaction than the LSS (compare Figures 2 and 3). Inflammatory responses, not seen in animals in the LSS-LD groups, were detected in both the MSS-LD-7d and MSS-LD-90d groups. Inflammatory reactions, which were mild in the MSS-LD-7d group, were mild to moderate in the lungs of the MSS-HD-7d group. Fibrosis was observed in the MSS-HD-90d group.

Ozone pretreatment followed by MSS instillation was used to emulate the oxidative and reactive nature of actual Martian soil. As expected, mice receiving such treatment showed a greater pulmonary toxicity response than those receiving either compound alone; the toxic manifestations were especially discernible in ozone-pretreated animals instilled with the high dose of MSS (compare Figures 3 and 4). The $\mathrm{O}_{3}+$ MSS-HD-7d group exhibited moderate pulmonary reactions with early focal moderate to severe fibrosis. The animals in the 90-day study had widespread intraalveolar debris, moderate alveolitis, and fibrosis. The effects of ozone and MSS coexposure appeared to be more than additive. Nevertheless, these effects were less severe than those seen in animals treated with high doses of crystalline silica.

Toxicity of lunar soil samples was investigated in the 1970s by NASA, but the data obtained were of limited usefulness for risk assessment. The studies involved intraperitoneal and subcutaneous injections of the lunar soil into mice and intratracheal instillation of the material into guinea pigs. The results showed acute inflammatory responses throughout the peritoneum or surrounding the subcutaneous injection site; low-grade inflammatory reactions, but no fibroblastic lesions, were detected 20 mo after the injection. In a study consisting of 3 groups of guinea pigs (4/group), 3 animals per group were each given $2 \mathrm{ml}$ saline containing $2 \%$ soil; the remaining animal was 
given saline containing no soil (Holland \& Simmonds, 1972). Two of the groups were killed either 2 or 4 days after the injection. No information was given on exactly when the third group, which was held for long-term observation, was killed. Without specifying the group(s), the authors reported that diffuse alveolar-cell hypertrophy, septal edema, mononuclear infiltration, and proliferation of alveolar macrophages were observed. The authors stated, "The tissue response seemed out of proportion to the amount of particle material present." Unable to discern the treatment effects because of a significant degree of spontaneous pulmonary pathology in both the control and dust-treated guinea pigs, the authors concluded that "the potentially harmful or innocuous nature of the dust remains to be investigated."

Toxicity data collected by Russian investigators are also of limited value. In one study mice were exposed for 4 days $(4 \mathrm{~h} /$ day $)$ to air $(0.5 \mathrm{~L} / \mathrm{min})$ that was "passed through a layer" consisting of a preweighed sample of lunar surface material (Kustov et al., 1974); no pathomorphological effects were detected and no information on weight loss after the air passed through the test material was reported. Another Russian study (Kustov et al., 1989) was conducted with Wistar rats, each injected intratracheally with a single dose of $50 \mathrm{mg}$ (in 1\% starch solution) of lunar dust or terrestrial analog (a basalt from Kamchatka, Russia). The compositions of the Russian lunar soil and terrestrial analog were comparable to U.S. counterparts. Six months after the dust treatment, the lung tissue revealed many fibrous cellular nodes that contained dust particles, macrophages, lymphocytes, plasmocytes, fibroblasts, and giant multinuclear cells. The terrestrial analog, like the extraterrestrial counterpart, also produced pneumoconiosis characterized by the development of fibrous cellular nodes, pronounced interstitial fibrosis, and interlobular septa.

These results are to be expected because of the massive dose of dust used by the Russian investigators. For example, Bermudez et al. (2000) reported that 13-wk exposures $\left(6 \mathrm{~h} /\right.$ day, 5 days/wk) of rats to $250 \mathrm{mg} / \mathrm{m}^{3}$ $\mathrm{TiO}_{2}$ (a dust that at low concentrations produces very little effect in rats) resulted in hypertrophy and hyperplasia of alveolar epithelium, and fibrotic changes; these effects were not seen in rats exposed to $50 \mathrm{mg} / \mathrm{m}^{3} \mathrm{TiO}_{2}$. The lung burden of dust in rats exposed to 250 or $50 \mathrm{mg} / \mathrm{m}^{3} \mathrm{TiO}_{2}$ determined at the end of the exposures was 40 or $8 \mathrm{mg} / \mathrm{rat}$, respectively. The bolus dose of $50 \mathrm{mg} / \mathrm{rat}$ in the Russian study apparently seriously overloaded the rats' lungs. It is well known that greatly overloading the lungs of rats with dust impairs cellular responses that clear and sequester particles, leading to a spectrum of histopathology that could include cancer (Trochimowicz, 1988; Muhle et al., 1990; Morrow, 1992; Hext, 1994). Thus, a conclusion could not be drawn from the results of Kustov et al. (1989) on whether lunar soil is fibrogenic at reasonable human exposure levels.

The overall results of the present study showed that LSS and MSS are not simply nuisance dusts. It is reasonable to predict that human inhala- 
tion exposures to LSS or MSS will produce more pulmonary responses than exposures to $\mathrm{TiO}_{2}$, but less severe responses than crystalline $\mathrm{SiO}_{2}$. Thus, workers using these dusts in test environments must use respiratory protection. The toxicity information and safety recommendation have been provided to the NASA Astromaterials Curator to generate material safety data sheets on the simulants. Even though the chemical compositions of these dust simulants are similar to lunar or Martian soil, the results of this study can give no more than a qualitative indication of the hazards of the actual extraterrestrial soils. The results of the coexposures to ozone and MSS suggest that Martian soil, a dust with a reactive surface and probably persistent in the lung like MSS, could produce more severe injury than that caused by the simulant alone. These findings support NASA's intention to evaluate the oxidative and reactive Martian surface soil before sending humans to the hostile Martian environment (Sullivan, 2000, personal communication). In the present study, the choice of doses, mice as the animal model, positive and negative controls, and intratracheal instillation as the route of exposure have enabled us to toxicologically evaluate these simulated extraterrestrial soils using very small amounts of materials. Thus, the design and methodology of the present study could be adopted for pulmonary toxicity studies on lunar dust and Martian dust.

\section{REFERENCES}

Adamson, I. Y., Prieditis, H., and Bowden, D. H. 1992. Instillation of chemotactic factor to silica-injected lungs lowers interstitial particle content and reduces pulmonary fibrosis. Am. J. Pathol. 141:319326.

Allen, C., Morris, R. V., Jager, K. M., Golden, D. C., Lindstrom, D. J., Lindstrom, M. M., and Lockwood, J. P. 1998. JSC Mars-1: A Martian soil simulant. Space 98 Proceedings of the Conference of American Society of Civil Engineers, pp. 469-475. 26-30 April, Albuquerque, NM.

Bermudez, E., Magum, J. B., Reverdy, E. E., Wong, B. A., Asgharian, B., Hext, P. M., Warheit, D. B., and Everitt, J. I. 2000. Pulmonary responses of rats, mice, and hamsters to inhaled titanium dioxide $\left(\mathrm{TiO}_{2}\right)$. Toxicologist 54:314.

Boggs, D. F. 1992. Comparative control of respiration. In Treatise on pulmonary toxicology, Vol. I: Comparative biology of the normal lung, ed. R. A. Parent, pp. 309-350. Boca Raton, FL: CRC Press.

Driscoll, K. E., Costa, D. L., Hatch, G., Henderson, R., Oberdorster, G., Salem, H., and Schlesinger, R. B. 2000. Intratracheal instillation as an exposure technique for the evaluation of respiratory tract toxicity: Uses and limitations. Toxicol. Sci. 55:24-35.

Everitt, J. I., Mangum J. B., Bermudez, E., Wong, B. A., Asgarian, B., Reverdy, E. E., Hext, P. M., and Warheit, D. B. 2000. Comparison of selected pulmonary responses of rats, mice, and Syrian golden hamsters to inhaled pigmentary titanium dioxide. Inhal. Toxicol. 12(suppl. 3):275-282.

Glaser, P. E. 1992. Mitigation of dust contamination during EVA operations on the moon and Mars. In Engineering, construction, and operations in space, III: Space'92: Proceedings of the 3rd International Conference, Denver, Colorado, May 31-June 4.

Henderson, R. F., Driscoll, K. E., Harkema, J. R., Lindenschmidt, R. C., Chang, I.-Y., Maples, K. R., and Barr, E. B. 1995. A comparison of the inflammatory response of the lung to inhaled versus instilled particles in F344 Rats. Fundam. Appl. Toxicol. 24:183-197.

Hext, P. M. 1994. Current perspectives on particulate induced pulmonary tumours. Hum. Exp. Toxicol. 13:700-715. 
Hoffman, S., and Kaplan, D. 1997. Human exploration of Mars: The reference mission of the NASA Mars exploration study team. NASA Special Publication 61-7, Linthicum Heights, MD: NASA Center for Aerospace Information.

Holland, J. M., and Simmonds, R. C. 1972. The mammalian response to lunar particulates. Space Life Sci. 4(1):97-109.

Kirichenko, A., Li, L., Morandi, M. T., and Holian, A. 1996. 4-Hydroxyl-2-nonenal-protein adducts and apoptosis in murine lung cells after acute ozone exposure. Toxicol. Appl. Pharmacol. 141:416424.

Kustov, V. V., Ostapvenko, O. F., and Petrukhin, V. G. 1974. [Research on the biological effect of a fine fraction of lunar soil sent to Earth by the unmanned station Luna-16]. In [Lunar soil from the Sea of Fertility], p. 592. Moscow: M. Nauka.

Kustov, V. V., Belkin, V. I., and Kruglikov, G. G. 1989. [Biological effects of lunar soil]. [Problems in Space Biology] 61:1-146.

Lai, Y.-L. 1992. Comparative ventilation of the normal lung. In Treatise on pulmonary toxicology, Vol. I: Comparative biology of the normal lung, ed. R. A. Parent, pp. 217-239. Boca Raton, FL: CRC Press.

Lam, C.-W., James, J. T., Latch, J. N., Hamilton R. F., and Holian, A. 2002. Pulmonary toxicity of simulated lunar and Martian dusts in mice: II. Biomarkers of acute responses after intratracheal instillation. Inhal. Toxicol. 14:917-928.

Leigh, J., Nonin, A., and Wang, H. 2000. In vivo genotoxicity of crystalline silica as evidenced by micronuclei in pulmonary alveolar macrophage: Low-dose study. Inhal. Toxicol. 12:199-204.

McKay, D. S., Carter, J. L., Boles, W. W., Allen, C. C., and Allton, J. H. 1994. JSC-1: A new lunar soil simulant. Proceedings of Space '94, Conference of American Society of Civil Engineers, 26 February-3 March, Albuquerque, NM.

Morrow, P. E. 1992. Dust overloading of the lungs: Update and appraisal. Toxicol. Appl. Pharmacol. 113:1-12.

Muhle, H., Bellmann, B., Creutzenberg, O., Heinrich, U., Ketkar, M., and Mermelstein, R. 1990. Dust overloading of lungs after exposure of rats to particles of low solubility: Comparative studies. J. Aerosol Sci. 21:374-377.

NASA. 1969. Apollo 11 technical crew debriefing. Houston, TX. Cited in Final report: Dust control and protection for planetary exposure. Prepared by Lockheed Engineering \& Sciences Company. NASA Document JSC-25975. Houston, TX: National Aeronautics and Space Administration, Johnson Space Center.

NASA. 1970. Apollo 12 preliminary science report. Washington, DC: NASA SP-235, Scientific and Technical Information, Division, Office of Technology Utilization, National Aeronautics and Space Administration.

Oyama, V. I., and Berdahl, B. J. 1977. The Viking gas exchange experiment results from Chryse and Utopia surface samples. J. Geophys. Res. 82:4669-4676.

Reuzel, P. G., Bruijntjes, J. P., Feron, V., and Woutersen, R. A. 1991. Subchronic inhalation toxicity of amorphous silicas and quartz dust in rats. Food Chem. Toxicol. 29(5):341-354.

Smith, W. B., Wilson, R. R., and Harris, D. B. 1979. A five-stage cyclone system for in situ sampling. Environ. Sci. Technol. 13:1387-1392.

Trochimowicz, H. J., Lee, K. P., and Reinhardt, C. F. 1988. Chronic inhalation exposure of rats to titanium dioxide dust. J. Appl. Toxicol. 8:383-385.

Tsapin, A. I., Goldeld, M. G., McDonald, G. D., Nealson, K. H., Moscowitz, B., Solheid, P., Kemner, K. H., Kelly, S. D., and Orlandini, K. A. 2000. Iron(VI): Hypothetical candidate for the Martian oxidant. Cirrus 147:68-79.

Yen, A. S., Kim, S. S., Hecht, M. H., Frant, M. S., and Murray, B. 2000. Evidence that the reactivity of the Martian soil is due to superoxide ions. Science 289:1909-1912. 